\title{
Usefulness of the Psoriatic Arthritis Screening and Evaluation Questionnaire to Monitor Disease Activity in Management of Patients with Psoriasis: Findings from the EPI-PSODE Study
}

Yong Beom Choe*, Chul Jong Park ${ }_{4}^{1, *}$, Dae Young $\mathrm{Yu}_{5}^{2}$, Youngdoe $\mathrm{Kim}_{6}^{2}$, Hyun Jeong Ju ${ }^{1}$, Sang Woong Youn ${ }^{3}$, Joo-Heung Lee ${ }^{4}$, Byung Soo Kim ${ }^{5}$, Seong Jun Seo ${ }^{6}$, Seok-Kweon Yun ${ }^{7}$, Joonsoo Park ${ }^{8}$, Nack In Kim ${ }^{9}$, Jai Il Youn ${ }^{10}$, Seok-Jong Lee ${ }^{11}$, Min-Geol Lee ${ }^{12}$, Kwang Joong Kim ${ }^{13}$, Young Suck Ro ${ }^{14}$, Hae Jun Song ${ }_{20}$, Bong Seok Shin ${ }^{16}$, Sung Ku Ahn ${ }^{17}$, Ji Yeoun Lee ${ }^{18}$, Young Ho Won ${ }^{19}$, Min Soo Jang ${ }^{20}$, Ki Ho Kim ${ }^{21}$, Myung Hwa Kim ${ }^{22}$, Tae Yoon Kim ${ }^{23}$, Jee-Ho Choi ${ }^{24}$

Department of Dermatology, Konkuk University School of Medicine, Seoul, ${ }^{1}$ Department of Dermatology, The Catholic University of Korea, Bucheon St. Mary's Hospital, Bucheon, ${ }^{2}$ Medical Affairs, Janssen Korea, Seoul, ${ }^{3}$ Department of Dermatology, Seoul National University Bundang Hospital, Seoul National University College of Medicine, Seongnam, ${ }^{4}$ Department of Dermatology, Samsung Medical Center, Sungkyunkwan University School of Medicine, Seoul, ${ }^{5}$ Department of Dermatology, Pusan National University School of Medicine, Busan, ${ }^{6}$ Department of Dermatology, Chung-Ang University Hospital, Seoul, ${ }^{7}$ Department of Dermatology, Chonbuk National University Medical School, Jeonju, ${ }^{8}$ Department of Dermatology, Catholic University of Daegu School of Medicine, Daegu, ${ }^{9}$ Department of Dermatology, Kyung Hee University Medical Center, Seoul, ${ }^{10}$ Department of Dermatology, National Medical Center, Seoul, ${ }^{11}$ Department of Dermatology, Kyungpook National University Hospital, Daegu, ${ }^{12}$ Department of Dermatology, Severance Hospital, Yonsei University College of Medicine, Seoul, ${ }^{13}$ Department of Dermatology, Hallym University Sacred Heart Hospital, Anyang, ${ }^{14}$ Department of Dermatology, Hanyang University Medical Center, Seoul, ${ }_{15}$ Department of Dermatology, Korea University Guro Hospital, Seoul, ${ }^{16}$ Department of Dermatology, Chosun University Hospital, Gwangju, ${ }^{17}$ Department of Dermatology, Wonju Severance Christian Hospital, Wonju, ${ }^{18}$ Department of Dermatology, Chungbuk National University College of Medicine, Cheongju, ${ }^{19}$ Department of Dermatology, Chonnam National University Hospital, Gwangju,

${ }^{20}$ Department of Dermatology, Kosin University College of Medicine, Busan, ${ }^{21}$ Department of Dermatology, Dong-A University Hospital, Busan, ${ }^{22}$ Department of Dermatology, Dankook University Hospital, Cheonan, ${ }^{23}$ Department of Dermatology, The Catholic University of Korea, Seoul St. Mary's Hospital, Seoul, ${ }^{24}$ Department of Dermatology, Asan Medical Center, University of Ulsan College of Medicine, Seoul, Korea

Background: Psoriasis and psoriatic arthritis (PsA) are included in the group of immune-mediated inflammatory diseases (IMIDs) caused by systemic inflammation; however, indicators for monitoring inflammatory activity in patients with psoriasis, such as the Psoriasis Area and Severity Index (PASI), are limited. Objective: To determine whether the Psoriatic Arthritis Screening and Evaluation (PASE) questionnaire can be used to monitor disease activity in patients with psoriasis. Methods: This was a multicenter, noninterventional, cross-sectional study. Demographic factors and PASI and PASE scores were collected to investigate associations between each. Results: PASE data were available for 1,255 patients, of whom $498(39.7 \%)$ had a score of $\geq 37$. Compared with the group with PASE score $<37$, the group with score $\geq 37$ had a higher proportion of women $(34.9 \%$ vs. $48.8 \%, p<0.0001$ ), older mean age at diagnosis (36.4 vs. 41.7 years, $p<0.0001$ ), more severe disease activity using PASI and body surface area measures $(p=0.0021$ and $p=0.0008$, respectively), and higher mean body mass index (23.7 vs. 24.1, $p=0.0411$ ). In a multiple linear regression model, PASE score was positively associated with cutaneous disease activity $(p<0.0001)$. Conclusion: After risk-adjustment, PASE was positively associated with PASI, which suggests that PASE can be sensitive to disease activity. Since psoriasis is regarded as one of the IMIDs, PASE may be utilized as a tool not only to screen PsA but also to monitor disease activity. (Ann Dermatol 31(1) $29 \sim 36,2019$ )

-Keywords-

Arthritis, Psoriatic

Received June 4, 2018, Revised July 17, 2018, Accepted for publication August 6, 2018

*These authors have equally contributed to the article.

Corresponding author: Jee-Ho Choi, Department of Dermatology, Asan Medical Center, University of Ulsan College of Medicine, 88 Olympic-ro 43-gil, Songpa-gu, Seoul 05505, Korea. Tel: 82-2-3010-3463, Fax: 82-2-486-7831, E-mail: cjhamc@naver.com ORCID: https://orcid.org/0000-0001-6139-9869

This is an Open Access article distributed under the terms of the Creative Commons Attribution Non-Commercial License (http://creativecommons. org/licenses/by-nc/4.0) which permits unrestricted non-commercial use, distribution, and reproduction in any medium, provided the original work is properly cited.

Copyright $\odot$ The Korean Dermatological Association and The Korean Society for Investigative Dermatology 


\section{INTRODUCTION}

Psoriasis is a chronic inflammatory skin disease with prevalence of $1 \% \sim 3 \%$ worldwide. Skin lesions are characterized by multiple, well-demarcated, raised, red plaques with a white scaly surface ${ }^{1}$. It is considered to be a systemic disease because it is frequently accompanied by comorbidities that include psoriatic arthritis (PsA), diabetes, dyslipidemia, and cardiovascular disease ${ }^{2,3}$. PsA is an inflammatory arthritis associated with psoriasis and its prevalence varies between $0.02 \%$ and $0.42 \%$ in the general population ${ }^{4,5}$ and between $6 \%$ and $48 \%$ in psoriasis patients ${ }^{6}$. The skin manifestations of psoriasis precede symptoms of arthritis by 10 years on average and, in $15 \%$ of the total cases, PsA and psoriasis either occur simultaneously or PsA precedes the skin disease ${ }^{7}$.

Early diagnosis of and prompt intervention for PsA are crucial because delaying treatment may result in devastating, irreversible joint damage. Moreover, PsA is known to be an important determinant of vascular comorbidities in psoriatic patients ${ }^{8}$. Dermatologists, therefore, have an important role in examining other body systems as well as the skin lesions associated with psoriasis that might be involved in this immune-mediated inflammatory disease (IMID).

However, there is no specific indicator for monitoring systemic inflammation in patients with psoriasis, such as the C-reactive protein levels used in clinical practice to monitor disease activity in rheumatic and inflammatory bowel disease. On the other hand, some screening tools have been developed for the identification of PsA in patients with psoriasis; these include the Psoriatic Arthritis Screening and Evaluation (PASE) $)^{9}$, the Psoriatic and Arthritic Questionnaire $^{10}$, the Psoriasis Epidemiology Screening Tool $^{11}$, the Toronto Psoriatic Arthritis Screen ${ }^{12}$, and the Early Arthritis for Psoriatic Patients ${ }^{13}$. Of these, PASE has the most questions, with possible scores of 0 to 75 , with a broader range to screen arthritis-related symptoms and functions. In this analysis, we sought to determine whether the symptoms of inflammatory arthritis, and their effect on patient functioning, are positively associated with cutaneous disease activity in order to enable better management of patients with psoriasis, in a holistic approach to IMID.

\section{MATERIALS AND METHODS}

\section{Study design}

The EPI-PSODE ${ }^{14}$ study was a multicenter, noninterventional, cross-sectional study. The 25 participating centers were primarily university hospitals, located across Korea (with the exception of the Jeju island region). This study was reviewed and approved by the Institutional Review Board of each center (Corresponding author's institution [Asan Medical Center]: IRB no. 2013-0161). To extract a representative sample reflecting the distribution of psoriasis in Korea, the numbers and locations of the study centers were selected on the basis of population distribution and health insurance reimbursement data of patients with psoriasis. Patients were examined and enrolled consecutively in order of visiting the center. After obtaining informed consent, all study procedures were performed on 1 day. The study patients were adults aged 20 years or older diagnosed with psoriasis. Data were collected by interviewing and assessing the patients on demographic factors (age, gender, height, weight, waist circumference, disease duration, age at diagnosis, family history in first-degree relative, drinking/smoking history, and medication history). Physical examinations for disease-severity measures (Psoriasis Area and Severity Index [PASI] and body surface area $[B S A]$ ) and blood pressure were performed. Quality of life was evaluated by the Dermatologic Life Quality Index (DLQI) and Medical Outcomes Study 36-Item Short-Form Health Survey (SF-36) ${ }^{15}$. In order to evaluate patient satisfaction with various therapies, questions from the existing Medication Satisfaction Questionnaire (MSQ) were included ${ }^{16}$. Lastly, the PASE tool was used to assess arthritis-related symptoms and functions.

\section{Statistical analysis}

Descriptive statistics for continuous variables are presented as means with standard deviation (SD), and dichotomous variables are presented as frequencies with percentages in parentheses. Respective proportions are presented using 37 points $^{17,18}, 44$ points $^{19}$, and 47 points $^{9}$ as cut-off values in PASE, and variables collected were compared to assess the statistical significance of any differences among the groups using a cutoff threshold of 37 points of PASE (PASE $<37$ and PASE 237 ) based on a validation study for Korean patients (sensitivity of $77.8 \%$, specificity of $82.3 \%$, positive predictive value of $37.8 \%$ and negative predictive value of $96.4 \%)^{17}$. We used, where appropriate, the Mann-Whitney U-test and t-test for continuous variables and Pearson's chi-square test and Fisher's exact test for dichotomous variables, without missing data imputation. In addition, multiple linear regression analysis was used to assess association between disease activity (using PASI) and inflammatory arthritis-related symptoms and functions (using PASE) after excluding the effect of each confounder such as gender, age, and body mass index (BMI) which are considerably related to occurrence of arthritis. All stat- 
istical tests were performed using 2-sided tests and $p$-values $<0.05$ were considered statistically significant. Analyses were performed using the statistical software package SAS 9.4 (Statistical Analysis System; SAS-Institute, Cary, NC, USA).

\section{RESULTS}

Of 1,260 patients who completed the study, PASE data were available for 1,255 patients. The proportions of patients scoring $\geq 47, \geq 44$, and $\geq 37$ points were $18.6 \%$ $(n=233), 24.0 \% \quad(n=301)$, and $39.7 \% \quad(n=498)$, respectively (Fig. 1).

At the 37-point cut-off, there were 757 patients in the group with PASE $<37$ and 498 in the group with PASE $\geq$ 37. The group with PASE $\geq 37$ had a higher proportion of women than the group with PASE $<37$ (48.8\% vs. $34.9 \%$, $p<0.0001)$; older mean age (50.5 years vs. 44.7 years, $p<$ $0.0001)$; and older mean age at diagnosis (41.7 years vs. 36.4 years, $p<0.0001)$. The higher-score PASE group (PASE $\geq 37$ ) had more severe disease activity using PASI and BSA (difference of PASI $=1.5 ; p=0.0021$ and difference of $\mathrm{BSA}=3.1 ; p=0.0008$, respectively) than the lower-score PASE group (PASE <37). Nail involvement and family history of psoriasis were more frequent in the PASE $\geq 37$ group but this did not reach statistical significance. The group with PASE $\geq 37$ had higher mean BMI (24.1 vs. $23.7, p=0.0411)$ and greater waist circumference (85.87 $\mathrm{cm}$ vs. $83.22 \mathrm{~cm}, p=0.0002$ ) but there was no significant relationship with blood pressure between the 2 groups. A significantly lower percentage of patients in the group with PASE $\geq 37$ had a smoking and drinking history than the group with PASE $<37$, but this appears to be affected by the difference in the gender ratio (no statistical significance based on Cochran-Mantel-Haenszel $[\mathrm{CMH}]$ test

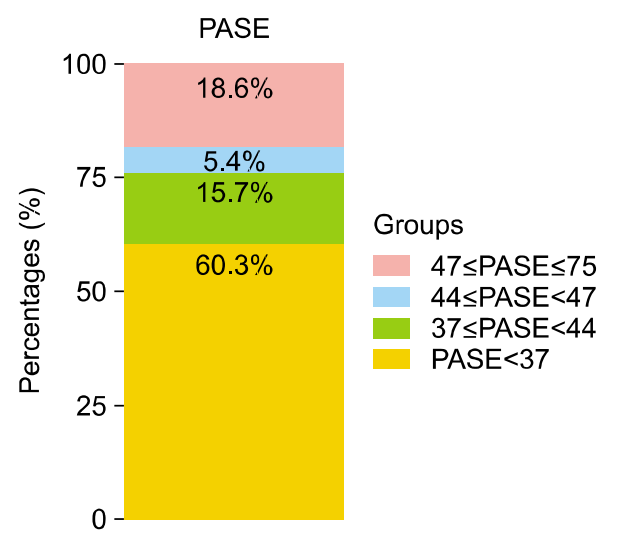

Fig. 1. Proportion of patients by PASE cut-off values. PASE: Psoriatic Arthritis Screening and Evaluation. between the 2 groups stratified by gender; smoking $(\mathrm{pCMH}=0.9297)$ and drinking $(\mathrm{pCMH}=0.1261)$ (data not shown). Regarding medication history, only use of systemic treatment was significantly greater in the group with PASE $\geq 37$ than the group with PASE $<37(66.3 \%$ vs. $58.0 \%, p=0.0032)$. DLQI and both physical and mental component SF-36 scores were significantly higher in the group with PASE $\geq 37$ compared to the group with PASE $<37$, and satisfaction with treatment was lower in the group with PASE $\geq 37$ ( $p=0.0015$ ) (Table 1 ).

A multiple linear regression model was used to explore the potential for an association between disease severity represented by PASI and PASE scores by designating factors with representativeness among significant independent variables in the univariate analysis. It appeared that female gender, age, and BMI affected arthritis symptoms and function. PASE and PASI were associated with each other, even after adjustment for the these factors $(p<0.0001)$ (Table 2).

The comparison of scores between the group with PASE $\geq 37$ and the group with PASE $<37$ for each question of the PASE questionnaire is shown in Fig. 2 and Table 3 for the symptom subscale and Fig. 3 and Table 4 for the function subscale. For the symptom subscale, the highest score difference between the 2 groups was for question 2, "My joints hurt". The highest score in both groups was for question 1, "I feel tired for most of the day", and the lowest score in both groups was for question 5, "My joints feel hot". This last question had the lowest score difference between the groups. For the function subscale, the score difference between the 2 groups was highest for question 8, "I feel that my joint problems have affected my ability to work", then question 12, "I am unable to be as active as I used to be" and question 13, "I feel stiff for more than 2 hours after waking up in the morning". Lastly, the question with the lowest score in both groups and the lowest score difference between the 2 groups was question 10 , "I have trouble wearing rings on my fingers or my watch".

\section{DISCUSSION}

The prevalence of PsA in Korea according to previous studies was approximately $9.0 \% \sim 14.1 \%{ }^{20-22}$. When PASE scores of $\geq 47, \geq 44$, and $\geq 37$ were applied as cut-off values, the proportions of screened patients in each group were $18.6 \%, 24.0 \%$, and $39.7 \%$, respectively. Of these, approximately $40 \%$ of patients with a cut-off score of $\geq 37$ validated in the Korean population may require additional assessments to confirm a diagnosis of PsA. In our study, the prevalence of PsA in patients with psoriasis was nu- 
Table 1. Comparison of related factors between 2 groups divided by PASE 37

\begin{tabular}{|c|c|c|c|c|}
\hline Category & $n^{\prime}$ & PASE $<37(n=757)$ & PASE $\geq 37 \quad(n=498)$ & $p$-value \\
\hline \multicolumn{5}{|l|}{ Demographics } \\
\hline Gender & 1,255 & & & \\
\hline Male & 748 & $493(65.1)$ & $255(51.2)$ & $<0.0001$ \\
\hline Female & 507 & $264(34.9)$ & $243(48.8)$ & \\
\hline Age $(y r)$ & 1,255 & $44.7 \pm 13.92$ & $50.5 \pm 14.66$ & $<0.0001$ \\
\hline Age at diagnosis (yr) & 1,252 & $36.4 \pm 15.72$ & $41.7 \pm 17.11$ & $<0.0001$ \\
\hline Disease duration (mo) & 1,252 & $106.6 \pm 121.13$ & $113.7 \pm 123.58$ & 0.3574 \\
\hline PASI & 1,255 & $6.87 \pm 6.409$ & $8.38 \pm 7.905$ & 0.0021 \\
\hline $\mathrm{BSA}$ & 1,253 & $11.9 \pm 13.21$ & $15.0 \pm 16.36$ & 0.0008 \\
\hline Nail involvement & 1,255 & $90(11.9)$ & $65(13.1)$ & 0.5401 \\
\hline Family history & 1,255 & $91(12.0)$ & $68(13.7)$ & 0.3947 \\
\hline BMI $\left(\mathrm{kg} / \mathrm{m}^{2}\right)$ & 1,254 & $23.70 \pm 3.308$ & $24.12 \pm 3.746$ & 0.0411 \\
\hline Waist circumference $(\mathrm{cm})$ & 1,108 & $83.22 \pm 10.218$ & $85.87 \pm 12.304$ & 0.0002 \\
\hline $\mathrm{SBP} \geq 140 \mathrm{mmHg}$ or $\mathrm{DBP} \geq 90 \mathrm{mmHg}$ & 1,160 & $134(19.3)$ & $97(20.9)$ & 0.4900 \\
\hline Smoking history & 1,255 & $391(51.7)$ & $216(43.4)$ & 0.0041 \\
\hline Drinking history & 1,255 & $512(67.6)$ & $291(58.4)$ & 0.0009 \\
\hline \multicolumn{5}{|l|}{ Medication history } \\
\hline Topical & 1,255 & $712(94.1)$ & $463(93.0)$ & 0.4420 \\
\hline Phototherapy & 1,255 & $394(61.7)$ & $245(49.2)$ & 0.3230 \\
\hline Systemics & 1,255 & $439(58.0)$ & $330(66.3)$ & 0.0032 \\
\hline Biologics & 1,255 & $38(5.0)$ & $34(6.8)$ & 0.1779 \\
\hline \multicolumn{5}{|l|}{ Patient-reported outcome } \\
\hline PASE total score & 1,255 & $24.8 \pm 6.81$ & $47.2 \pm 7.95$ & $<0.0001$ \\
\hline PASE symptom score & 1,255 & $12.2 \pm 3.64$ & $22.0 \pm 4.08$ & $<0.0001$ \\
\hline PASE function score & 1,255 & $12.6 \pm 4.17$ & $25.2 \pm 5.01$ & $<0.0001$ \\
\hline DLQI & 1,251 & $10.3 \pm 6.80$ & $14.6 \pm 7.12$ & $<0.0001$ \\
\hline SF-36 (physical) & 1,253 & $52.1 \pm 6.07$ & $43.8 \pm 7.86$ & $<0.0001$ \\
\hline SF-36 (mental) & 1,253 & $46.0 \pm 10.29$ & $37.4 \pm 10.61$ & $<0.0001$ \\
\hline Satisfaction in MSQ & 1,250 & $461(61.2)$ & $271(54.5)$ & 0.0015 \\
\hline
\end{tabular}

Values are presented as number (\%) or mean \pm standard deviation. Percentages were based on the total number of subjects with each available result in each group. n': Total number of subjects with each available result, PASE: Psoriatic Arthritis Screening and Evaluation, PASI: Psoriasis Area and Severity Index, BSA: body surface area, BMI: body mass index, SBP: systolic blood pressure, DBP: diastolic blood pressure, DLQI: Dermatology Life Quality Index, SF-36: Medical Outcomes Study 36-Item Short-Form Health Survey, MSQ: Medication Satisfaction Questionnaire.

Table 2. Association between PASE and PASI in a multiple linear regression model

\begin{tabular}{lcc}
\hline \multirow{2}{*}{ Variable } & \multicolumn{2}{c}{ PASE } \\
\cline { 2 - 3 } & $\beta$ & $p$-value \\
\hline PASI & 0.235 & $<0.0001$ \\
Female gender & 3.920 & $<0.0001$ \\
Age & 0.161 & $<0.0001$ \\
BMI & 0.136 & 0.2014 \\
\hline
\end{tabular}

PASE: Psoriatic Arthritis Screening and Evaluation, PASI: Psoriasis Area and Severity Index, $\beta$ : regression coefficient, BMI: body mass index.

merically estimated to be $15.0 \%$ by applying positive predictive value of $37.8 \%$ to the patients screened with a cut-off of 37 points $^{17}$. In addition, a recent study per- formed in Japan showed that the prevalence of PsA in patients with psoriasis reached around $20 \%$ in some areas ${ }^{23}$. Continued studies are required to further characterize the prevalence of PsA in Korea.

The maximum score for the PASE is 75; for a continuous variable with such a wide range, the ability to detect changes becomes relatively greater and sensitivity is higher than a continuous variable with a narrow range. In general, most patients who develop PsA progress from psoriasis alone to psoriasis with PSA and these patients have more severe psoriasis ${ }^{24}$; this finding aligns with our analysis in which the group with PASE $\geq 37$ showed higher PASI scores and BSA affected than the group with PASE $<37$. Moreover, disease severity in psoriasis is associated with elevated proinflammatory cytokines ${ }^{25}$ and this level of inflammation is related to the development of hyper- 
tension $^{26}$. A systematic review found that there is a greater prevalence of hypertension in patients with psoriasis, and patients with severe psoriasis are more likely to have hypertension than those with mild psoriasis ${ }^{27}$, consistent with hypertension considered as a type of inflammatory

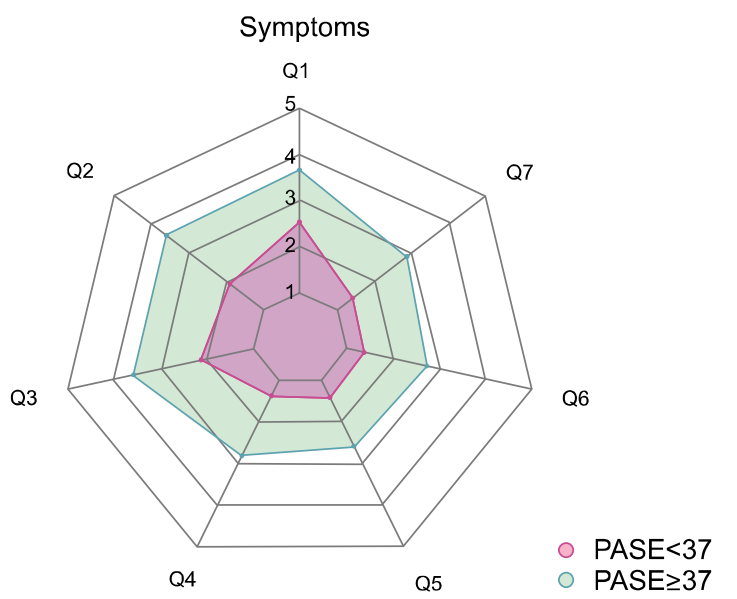

Fig. 2. Comparisons in symptom subscale of PASE. PASE: Psoriatic Arthritis Screening and Evaluation. disease ${ }^{28}$.

The disease severity of psoriasis has been shown to be related to the activity of inflammation. In our analysis, PASE scores were positively associated with PASI scores after

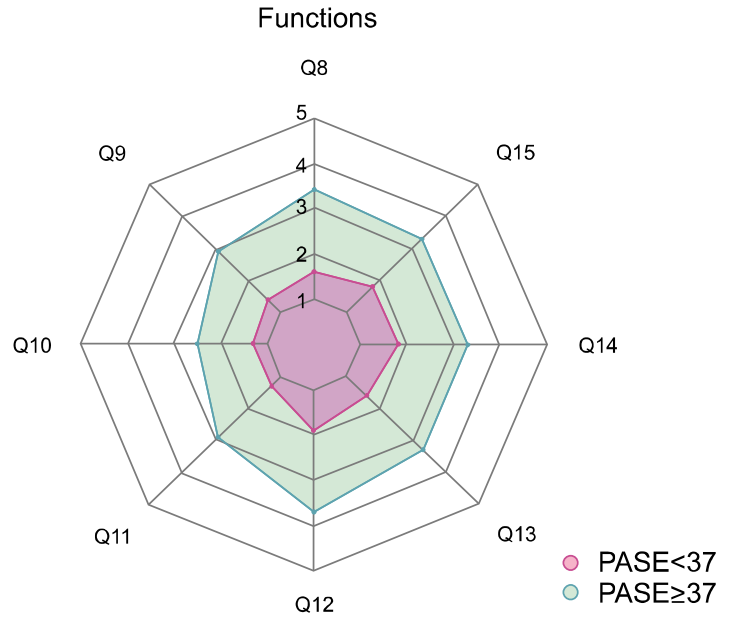

Fig. 3. Comparisons in function subscale of PASE. PASE: Psoriatic Arthritis Screening and Evaluation.

Table 3. Comparisons in symptom subscale of PASE

\begin{tabular}{lccc}
\hline \multicolumn{1}{c}{ PASE Questionnaire } & PASE $<37(\mathrm{n}=757)$ PASE $\geq 37(\mathrm{n}=498)$ & Difference \\
\hline 1. I feel tired for most of the day & $2.5 \pm 1.10$ & $3.7 \pm 0.87$ & $-1.2 \pm 1.01$ \\
2. My joints hurt & $1.9 \pm 0.99$ & $3.6 \pm 0.92$ & $-1.7 \pm 0.96$ \\
3. My back hurts & $2.1 \pm 1.11$ & $3.6 \pm 0.92$ & $-1.5 \pm 1.04$ \\
4. My joints become swollen & $1.4 \pm 0.63$ & $2.8 \pm 1.07$ & $-1.4 \pm 0.83$ \\
5. My joints feel "hot" & $1.4 \pm 0.61$ & $2.6 \pm 1.04$ & $-1.2 \pm 0.81$ \\
6. Occasionally, an entire finger or toe becomes swollen, making & $1.4 \pm 0.68$ & $2.7 \pm 1.12$ & $-1.3 \pm 0.88$ \\
it look like a "sausage" & & \\
7. I have noticed that the pain in my joints moves from one joint & $1.4 \pm 0.66$ & $2.9 \pm 1.09$ & $-1.4 \pm 0.85$ \\
to another, e.g. my wrist will hurt for a few days then my knee & & \\
$\quad$ will hurt and so on & & \\
\hline
\end{tabular}

Values are presented as mean \pm standard deviation. Difference $=$ PASE $\geq 37-$ PASE $<37$. PASE: Psoriatic Arthritis Screening and Evaluation.

Table 4. Comparisons in function subscale of PASE

\begin{tabular}{|c|c|c|c|}
\hline PASE Questionnaire & PASE $<37(n=757)$ & PASE $\geq 37(n=498)$ & Difference \\
\hline 8. I feel that my joint problems have affected my ability to work & $1.6 \pm 0.82$ & $3.4 \pm 1.01$ & $-1.9 \pm 0.90$ \\
\hline $\begin{array}{l}\text { 9. My joint problems have affected my ability to care for myself, } \\
\text { e.g. getting dressed or brushing my teeth }\end{array}$ & $1.4 \pm 0.70$ & $2.9 \pm 1.08$ & $-1.5 \pm 0.87$ \\
\hline 10. I have had trouble wearing rings on my fingers or my watch & $1.3 \pm 0.63$ & $2.5 \pm 1.11$ & $-1.2 \pm 0.86$ \\
\hline 11. I have had trouble getting into or out of a car & $1.3 \pm 0.59$ & $2.9 \pm 1.11$ & $-1.5 \pm 0.84$ \\
\hline 12. I am unable to be as active as I used to be & $1.9 \pm 1.02$ & $3.7 \pm 0.97$ & $-1.8 \pm 1.00$ \\
\hline 13. I feel stiff for more than 2 hours after waking up in the morning & $1.6 \pm 0.80$ & $3.3 \pm 1.00$ & $-1.7 \pm 0.88$ \\
\hline 14. The morning is the worst time of day for me & $1.8 \pm 0.95$ & $3.3 \pm 1.01$ & $-1.5 \pm 0.97$ \\
\hline $\begin{array}{l}\text { 15. It takes me a few minutes to get moving to the best of my ability, } \\
\text { any time of the day }\end{array}$ & $1.8 \pm 0.92$ & $3.3 \pm 0.94$ & $-1.5 \pm 0.93$ \\
\hline
\end{tabular}

Values are presented as mean \pm standard deviation. Difference $=$ PASE $\geq 37-$ PASE $<37$. PASE: Psoriatic Arthritis Screening and Evaluation. 
adjusting for confounding factors such as female gender, age, and BMI which affect arthritis symptoms and our result also showed positive linearity through each regression coefficient $(\beta)$ in Table 2 . In addition, Husni et al. ${ }^{29}$ confirmed that the PASE tool is sensitive to changes in response of patients treated with biological therapy, which might be applied similarly to change in disease activity or systemic inflammation. Therefore, the use of PASE could monitor changes in inflammatory activity, in other words disease activity, in patients with psoriasis. PASE is not only used for PsA screening but also for management of psoriasis as an IMID. Patients with PsA showed more severe psoriasis than patients without PSA in some studies ${ }^{24,30,31}$. In line with these results, our analysis showed that the group with PASE $\geq 37$ had significantly higher PASI and BSA affected than the group with PASE $<37$; greater and more active systemic inflammation may affect many body systems so this increased disease activity may promote the development of PsA. The most common identified risk factor for development of PsA was the presence of nail disease in many studies ${ }^{30,32,33}$. In our study, nail involvement was higher in the group with PASE $\geq 37$ than the group with PASE $<37$, but this was not statistically significant. Obesity has also been shown to increase the risk of occurrence of PsA in some studies ${ }^{34,35}$; this suggests that weight loss may alleviate disease severity and reduce the risk of developing PsA. Consistent with this, the BMI of the group with PASE $\geq 37$ was significantly higher in our study than that of the group with PASE $<37$. However, further studies are needed to determine the relationship between obesity and development of PsA in Korean patients with psoriasis because the difference in BMl between groups was small $\left(0.42 \mathrm{~kg} / \mathrm{m}^{2}\right)$ and weight gain may increase the risk of osteoarthritis, which is not related to systemic inflammation $^{36}$.

The association between smoking/drinking and PsA is controversial because there have been opposing results from a variety of studies ${ }^{37}$. In our analysis, the percentage of patients with a history of smoking was higher in the group with PASE $<37$ using a univariate model, though there was no statistically significant difference between the 2 groups when stratified by gender. In other words, no association between smoking and PASE score was identified in our analysis. Drinking was also not associated with PsA when stratified by gender. Tey et al. ${ }^{38}$ reported that sex, age of onset of psoriasis, and a family history of psoriasis were not associated with PsA, but our study showed that age at diagnosis was significantly higher in the group with PASE $\geq 37$ than the group with PASE $<37$.

A potential limitation of the PASE questionnaire is its length, and it may be difficult for patients to complete all
15 questions in the real-world setting of dermatology clinic practice. However, it may be sufficient to use only the questions that showed the greatest difference between the two groups. Question 2, "My joints hurt" in the symptom subscale and question 8, "I feel that my joint problems have affected my ability to work" showed the greatest difference between the 2 groups in our analysis. According to the Turkish PASE tool validation study ${ }^{39}$, questions 2, 8, and 12 indicated the highest sensitivity (77\%) for the answers "agree" or "strongly agree". This result is closely aligned with our analysis. If the scores for these questions are increased, physicians may consider completing the entire PASE questionnaire with the patient or performing regular follow-up, at least once every 6 or 12 months so that changes in inflammatory activity, which might not be apparent by examination of the skin, may be checked by evaluation of joint symptoms. Lastly, further studies are needed to support results from the present study. For example, a study on specific population excluding confounders could be conducted or a study to follow up changes in intra-subject setting.

In conclusion, PASE scores is independently associated with PASI scores after risk adjustment and can be sensitive to disease activity. From the perspective that psoriasis is treated as one of the IMIDs, PASE may be utilized as a tool to monitor changes in inflammatory activity and their effect on the course of the disease.

\section{ACKNOWLEDGMENT}

This study was sponsored by Janssen Korea Ltd.

\section{CONFLICTS OF INTEREST}

Dae Young $\mathrm{Yu}$ and Youngdoe Kim are employees of Janssen Korea. Other authors have no conflict of interest to declare.

\section{ORCID}

Yong Beom Choe, https://orcid.org/0000-0002-3074-7602 Chul Jong Park, https://orcid.org/0000-0003-3099-4109 Dae Young Yu, https://orcid.org/0000-0003-1091-5792 Youngdoe Kim, https://orcid.org/0000-0002-0772-6360 Hyun Jeong Ju, https://orcid.org/0000-0003-2711-3112 Sang Woong Youn, https://orcid.org/0000-0002-5602-3530 Joo-Heung Lee, https://orcid.org/0000-0002-1121-2055 Byung Soo Kim, https://orcid.org/0000-0003-0054-8570 Seong Jun Seo, https://orcid.org/0000-0003-2915-839X Seok-Kweon Yun, https://orcid.org/0000-0002-1498-3701 Joonsoo Park, https://orcid.org/0000-0003-1354-2311 
Nack In Kim, https://orcid.org/0000-0002-4810-7013 Jai II Youn, https://orcid.org/0000-0002-0401-2880 Seok-Jong Lee, https://orcid.org/0000-0002-6131-632X Min-Geol Lee, https://orcid.org/0000-0001-7040-5335 Kwang Joong Kim, https://orcid.org/0000-0003-3192-839X Young Suck Ro, https://orcid.org/0000-0002-6083-0351 Hae Jun Song, https://orcid.org/0000-0002-3171-3869 Bong Seok Shin, https://orcid.org/0000-0001-9618-1763 Sung Ku Ahn, https://orcid.org/0000-0003-0978-9426 Ji Yeoun Lee, https://orcid.org/0000-0001-9269-6591 Young Ho Won, https://orcid.org/0000-0003-4640-4337 Min Soo Jang, https://orcid.org/0000-0002-5686-0830 Ki Ho Kim, https://orcid.org/0000-0001-5389-5053 Myung Hwa Kim, https://orcid.org/0000-0002-9072-201X Tae Yoon Kim, https://orcid.org/0000-0001-8749-6085 Jee-Ho Choi, https://orcid.org/0000-0001-6139-9869

\section{REFERENCES}

1. Fitzpatrick TB, Goldsmith LA. Fitzpatrick's dermatology in general medicine. 8th ed. New York: McGraw-Hill Professional, 2012.

2. Gisondi P, Girolomoni G. Cardiometabolic comorbidities and the approach to patients with psoriasis. Actas Dermosifiliogr 2009;100 Suppl 2:14-21.

3. Davidovici BB, Sattar N, Prinz J, Puig L, Emery P, Barker JN, et al. Psoriasis and systemic inflammatory diseases: potential mechanistic links between skin disease and co-morbid conditions. J Invest Dermatol 2010;130:1785-1796.

4. Ficco HM, Citera G, Cocco JA. Prevalence of psoriatic arthritis in psoriasis patients according to newer classification criteria. Clin Rheumatol 2014;33:1489-1493.

5. Catanoso M, Pipitone N, Salvarani C. Epidemiology of psoriatic arthritis. Reumatismo 2012;64:66-70.

6. Gladman DD. Psoriatic arthritis from Wright's era until today. J Rheumatol Suppl 2009;83:4-8.

7. Ritchlin CT, Colbert RA, Gladman DD. Psoriatic arthritis. N Engl J Med 2017;376:957-970.

8. Chin YY, Yu HS, Li WC, Ko YC, Chen GS, Wu CS, et al. Arthritis as an important determinant for psoriatic patients to develop severe vascular events in Taiwan: a nation-wide study. J Eur Acad Dermatol Venereol 2013;27:1262-1268.

9. Husni ME, Meyer KH, Cohen DS, Mody E, Qureshi AA. The PASE questionnaire: pilot-testing a psoriatic arthritis screening and evaluation tool. J Am Acad Dermatol 2007;57:581-587.

10. Alenius GM, Stenberg B, Stenlund H, Lundblad M, Dahlqvist SR. Inflammatory joint manifestations are prevalent in psoriasis: prevalence study of joint and axial involvement in psoriatic patients, and evaluation of a psoriatic and arthritic questionnaire. J Rheumatol 2002;29:2577-2582.

11. Ibrahim GH, Buch MH, Lawson C, Waxman R, Helliwell PS. Evaluation of an existing screening tool for psoriatic arthritis in people with psoriasis and the development of a new instrument: the Psoriasis Epidemiology Screening Tool (PEST) questionnaire. Clin Exp Rheumatol 2009;27:469-474.
12. Gladman DD, Schentag CT, Tom BD, Chandran V, Brockbank J, Rosen C, et al. Development and initial validation of a screening questionnaire for psoriatic arthritis: the Toronto Psoriatic Arthritis Screen (ToPAS). Ann Rheum Dis 2009;68:497-501.

13. Tinazzi I, Adami S, Zanolin EM, Caimmi C, Confente S, Girolomoni $\mathrm{G}$, et al. The early psoriatic arthritis screening questionnaire: a simple and fast method for the identification of arthritis in patients with psoriasis. Rheumatology (Oxford) 2012;51:2058-2063.

14. Song HJ, Park CJ, Kim TY, Choe YB, Lee SJ, Kim NI, et al. The clinical profile of patients with psoriasis in Korea: a nationwide cross-sectional study (EPI-PSODE). Ann Dermatol 2017;29:462-470.

15. Ware JE Jr, Sherbourne CD. The MOS 36-item short-form health survey (SF-36). I. Conceptual framework and item selection. Med Care 1992;30:473-483.

16. Vernon MK, Revicki DA, Awad AG, Dirani R, Panish J, Canuso CM, et al. Psychometric evaluation of the Medication Satisfaction Questionnaire (MSQ) to assess satisfaction with antipsychotic medication among schizophrenia patients. Schizophr Res 2010;118:271-278.

17. You HS, Kim GW, Cho HH, Kim WJ, Mun JH, Song M, et al. Screening for psoriatic arthritis in Korean psoriasis patients using the Psoriatic Arthritis Screening Evaluation questionnaire. Ann Dermatol 2015;27:265-268.

18. Shin D, Kim HJ, Kim DS, Kim SM, Park JS, Park YB, et al. Clinical features of psoriatic arthritis in Korean patients with psoriasis: a cross-sectional observational study of 196 patients with psoriasis using psoriatic arthritis screening questionnaires. Rheumatol Int 2016;36:207-212.

19. Dominguez PL, Husni ME, Holt EW, Tyler S, Qureshi AA. Validity, reliability, and sensitivity-to-change properties of the psoriatic arthritis screening and evaluation questionnaire. Arch Dermatol Res 2009;301:573-579.

20. Baek HJ, Yoo CD, Shin KC, Lee YJ, Kang SW, Lee EB, et al. Spondylitis is the most common pattern of psoriatic arthritis in Korea. Rheumatol Int 2000;19:89-94.

21. Choi HJ, Lee YJ, Park JJ, Lee JC, Lee EY, Lee EB, et al. Clinical features of Korean patients with psoriatic arthritis. Korean J Med 2008;74:418-425.

22. Oh EH, Ro YS, Kim JE. Epidemiology and cardiovascular comorbidities in patients with psoriasis: a Korean nationwide population-based cohort study. J Dermatol 2017;44:621-629.

23. Ohara Y, Kishimoto M, Takizawa N, Yoshida K, Okada M, Eto $\mathrm{H}$, et al. Prevalence and clinical characteristics of psoriatic arthritis in Japan. J Rheumatol 2015;42:1439-1442.

24. Haroon M, Kirby B, FitzGerald O. High prevalence of psoriatic arthritis in patients with severe psoriasis with suboptimal performance of screening questionnaires. Ann Rheum Dis 2013;72:736-740.

25. Dowlatshahi EA, van der Voort EA, Arends LR, Nijsten T. Markers of systemic inflammation in psoriasis: a systematic review and meta-analysis. Br J Dermatol 2013;169:266-282.

26. Sesso HD, Buring JE, Rifai N, Blake GJ, Gaziano JM, Ridker PM. C-reactive protein and the risk of developing hypertension. JAMA 2003;290:2945-2951. 
27. Armstrong AW, Harskamp CT, Armstrong EJ. The association between psoriasis and hypertension: a systematic review and meta-analysis of observational studies. J Hypertens 2013;31:433-442.

28. Solak Y, Afsar B, Vaziri ND, Aslan G, Yalcin CE, Covic A, et al. Hypertension as an autoimmune and inflammatory disease. Hypertens Res 2016;39:567-573.

29. Husni ME, Qureshi AA, Koenig AS, Pedersen R, Robertson D. Utility of the PASE questionnaire, psoriatic arthritis (PsA) prevalence and PSA improvement with anti-TNF therapy: results from the PRISTINE trial. J Dermatolog Treat 2014; 25:90-95.

30. Eder L, Haddad A, Rosen CF, Lee KA, Chandran V, Cook R, et al. The incidence and risk factors for psoriatic arthritis in patients with psoriasis: a prospective cohort study. Arthritis Rheumatol 2016;68:915-923.

31. Gelfand JM, Gladman DD, Mease PJ, Smith N, Margolis DJ, Nijsten T, et al. Epidemiology of psoriatic arthritis in the population of the United States. J Am Acad Dermatol 2005; 53:573.

32. Langenbruch A, Radtke MA, Krensel M, Jacobi A, Reich K, Augustin M. Nail involvement as a predictor of concomitant psoriatic arthritis in patients with psoriasis. $\mathrm{Br}$ J Dermatol 2014;171:1123-1128.

33. Wilson FC, Icen M, Crowson CS, McEvoy MT, Gabriel SE,
Kremers HM. Incidence and clinical predictors of psoriatic arthritis in patients with psoriasis: a population-based study. Arthritis Rheum 2009;61:233-239.

34. Love TJ, Zhu Y, Zhang Y, Wall-Burns L, Ogdie A, Gelfand $J M$, et al. Obesity and the risk of psoriatic arthritis: a population-based study. Ann Rheum Dis 2012;71:1273-1277.

35. Li W, Han J, Qureshi AA. Obesity and risk of incident psoriatic arthritis in US women. Ann Rheum Dis 2012;71: 1267-1272.

36. Thijssen E, van Caam A, van der Kraan PM. Obesity and osteoarthritis, more than just wear and tear: pivotal roles for inflamed adipose tissue and dyslipidaemia in obesity-induced osteoarthritis. Rheumatology (Oxford) 2015;54:588-600.

37. Ogdie A, Gelfand JM. Clinical risk factors for the development of psoriatic arthritis among patients with psoriasis: a review of available evidence. Curr Rheumatol Rep 2015;17:64.

38. Tey HL, Ee HL, Tan AS, Theng TS, Wong SN, Khoo SW. Risk factors associated with having psoriatic arthritis in patients with cutaneous psoriasis. J Dermatol 2010;37:426430.

39. Oyur KB, Engin B, Hatemi G, Asma A, Kutlubay Z, Bulut N, et al. Turkish PASE: Turkish version of the psoriatic arthritis screening and evaluation questionnaire. Ann Dermatol 2014;26:457-461. 